\title{
Social Media Mapping as Digital Infrastructure for Disaster Prevention and Reduction
}

\author{
Kayoko Yamamoto, ${ }^{1, *}$ \\ ${ }^{1}$ Graduate School of Informatics and Engineering, University of Electro-Communications, Tokyo, 1- \\ 5-1 Chofugaoka Chofu-shi Tokyo Japan
}

\begin{abstract}
At the time of the Heavy Rain Disaster in Western Japan in July, 2018, it was possible to gather and accumulate a variety of disaster information using the function of social media mapping included in our spatiotemporal information system. Considering these circumstances and taking up the above social media mapping, the present study described the issues related to the development and utilization of digital infrastructures as one of the measures for disaster prevention and reduction. As the results of the present study, it is possible to rescue and support victims, and cause excessive information and confusion, due to the close relationship between the real and virtual space in the super smart society of Japan. Additionally, it is essential to effectively utilize the information included in the virtual space at the time of disaster. Specifically, it is an important issue to make use of the information on social media for rescue in the real space. Furthermore, it is necessary to take the measures for the people vulnerable to disaster who require the disaster information most. For this, it is necessary to prepare a variety of ICT in addition to oral communication.
\end{abstract}

\section{Introduction}

In Japan, the Basic Law on the Formation of an Advanced Information and Telecommunications (IT) Network Society (Basic IT Law) was put into effect in 2000. Therefore, this year is the start of the era of the Information and Telecommunications Network Society in Japan. During the first half of the 2010s, there was a transition from the ubiquitous network society that was aimed for the u-Japan policy to the cloud computing society that makes it possible to access the Internet with diverse information tools at any time in any place. Furthermore, the cloud computing society has been already developed all over the world, and information and communication technology (ICT) has become powerful tools for the general public in addition to scientists and technicians.

Thus, in recent Japan, it is the times of IoT (Internet of Things) and IoE (Internet of Everything) when various things were connected to the Internet. In the 5th Science and Technology Basic Plan (2016), merging the physical space (real world) and the cyberspace (virtual space) by maximally utilizing ICT, it is essential to promote realizing a "super smart society (Society 5.0)" that can bring wealth to the people.

* Corresponding author: kayoko.yamamoto@uec.ac.jp 
Fig. 1 describes the change of means of information communication after the Great Hanshin Earthquake (1995). As clearly shown in Fig. 1, the development of computerization since the Great Hanshin Earthquake was remarkable, and the information environment that surrounded us was radically changing. At the time of the Great Hanshin Earthquake, mobile information terminals hardly spread, and the penetrate rate of PCs was $22.3 \%$. However, at the time of the Great East Japan Earthquake (2011), the penetrate rate of mobile information terminals $(94.5 \%)$ was higher than that of PCs $(77.3 \%)$, and the general public accessed to the Internet using the former rather than the latter.

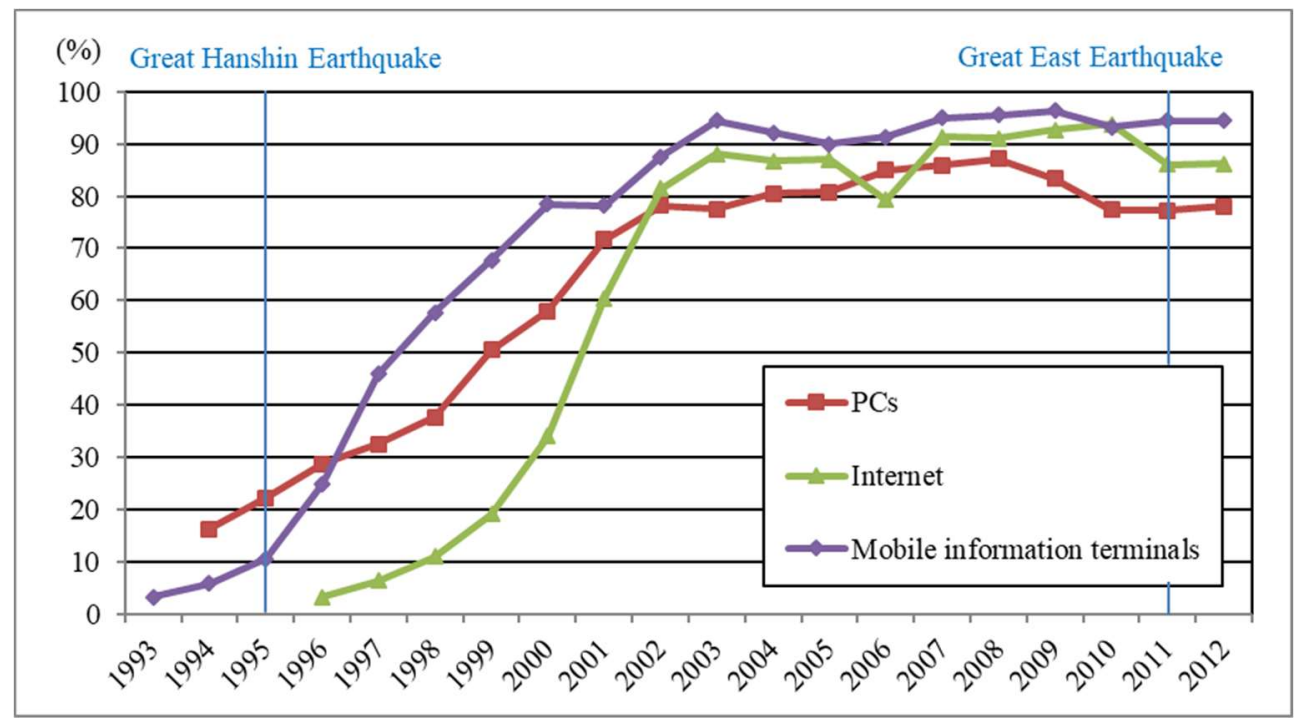

Fig. 1. Change of means of information communication after the Great Hanshin Earthquake (1995).

Note) Cabinet Office (2013) Consumer Confidence Survey in 2013.

Additionally, in recent years, the spread of various social media is remarkable all over the world. Though mass media is limited to one-way information transmission, social media allow us interactive information transmission and reception. Using social media, everyone can freely submit and receive information, view a variety of information submitted from all over the world, and transmit information not only with words but with complex formats combining moving images.

On the other hand, in recent years, because the occurrence frequency of meteorological disasters such as typhoon, local heavy rain and heavy snow in addition to earthquake and volcanic eruption tremendously increases, it is the most important issue to adopt the effective measures for disaster prevention and reduction around the world. Additionally, as the digital infrastructures are toughened in the above measures, the importance of ICT and social media is widely recognized especially in modern Japan.

At the time of the Heavy Rain Disaster in Western Japan in July, 2018, it was possible to gather and accumulate a variety of disaster information using the function of social media mapping included in the spatiotemporal information system developed by Makino et al. (2019). The heavy rain disaster had been caused by the torrential rains influenced by Typhoon No.7 and the seasonal rain front during the period from June 23th to July 8th. 15 prefectures surfed tremendous damages by the heavy rain disaster, and there were a lot of stricken areas especially in the western Japan. Considering these circumstances and taking up the above social media mapping, the present study described the issues related to the development and 
utilization of digital infrastructures as one of the measures for disaster prevention and reduction.

\section{Utilization of social media mapping at the time of the Heavy Rain Disaster in Western Japan in 2018}

\subsection{Spatiotemporal information system and function of social media mapping}

The spatiotemporal information system was developed integrating social networking services (SNS), Web-GIS (geographic information systems), mixed reality (MR) and the gallery system as well as Wikitude, and connecting external social media as show in Fig.2. Virtual reality (VR) can be defined as a synthetic or virtual environment which gives a person a sense of reality, and augmented reality (AR) can be defined to supplement the real space with virtual (computer-generated) objects that appear to co-exist in the same space as the real space. Furthermore, both VR and AR are integrated into MR which is used in the systems for entertainment, e-sports and sightseeing.

Web-GIS is provided by the Environmental Systems Research Institute, Inc. (ESRI). The function of social media mapping was implemented by the combination of Web-GIS and external social media. Using the above function, all of the information with location information submitted from social media such as Twitter, Flickr, Instagram, YouTube and Webcamera can be gathered and displayed on the 2D digital map of Web-GIS.

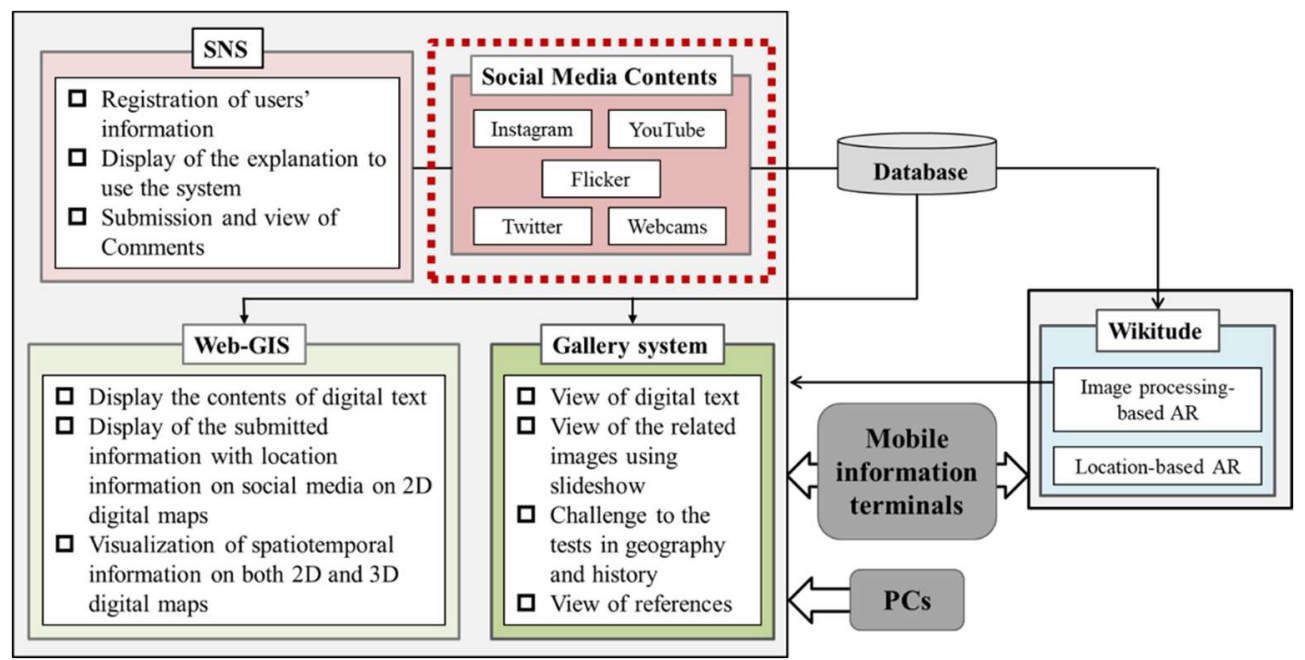

Fig. 2. System design of spatiotemporal information system.

\subsection{Utilization of social media mapping at the times of the heavy rain disaster}

When a tremendously heavy rain occurred in the western part of Japan especially in July, 2018 , a variety of information with images related to the disaster submitted from social media was accumulated and displayed on the 2D digital map included in the function of social media mapping. Fig. 3 describes the screen for the function of social media mapping at time of the Heavy Rain Disaster in Western Japan in 2018, targeting Setouchi Region which is a part of western Japan and is a tremendously damaged area. From this, it is evident that the submitted 
information started increasing just before the time of the heavy rain disaster, and it concentrated on the stricken areas.

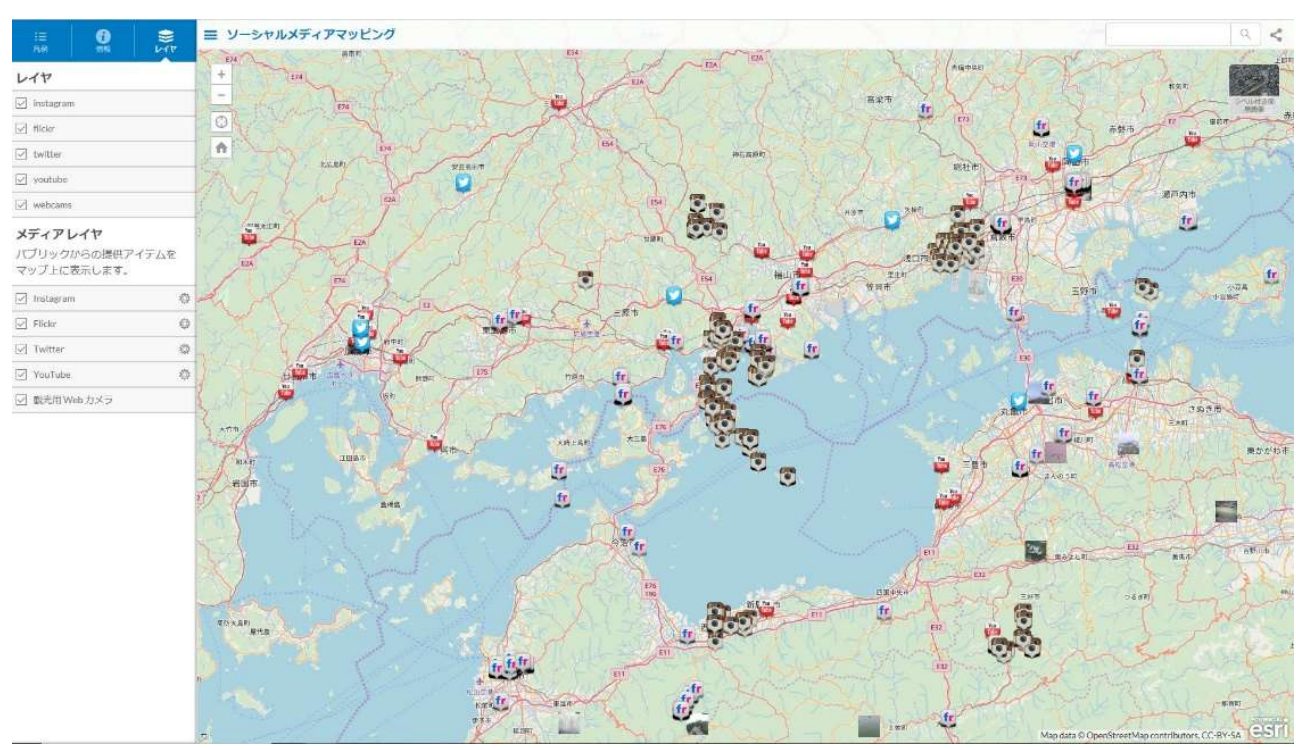

Fig. 3. Screen for the function of social media mapping at the time of the Heavy Rain Disaster in Western Japan in 2018, targeting Setouchi Region.

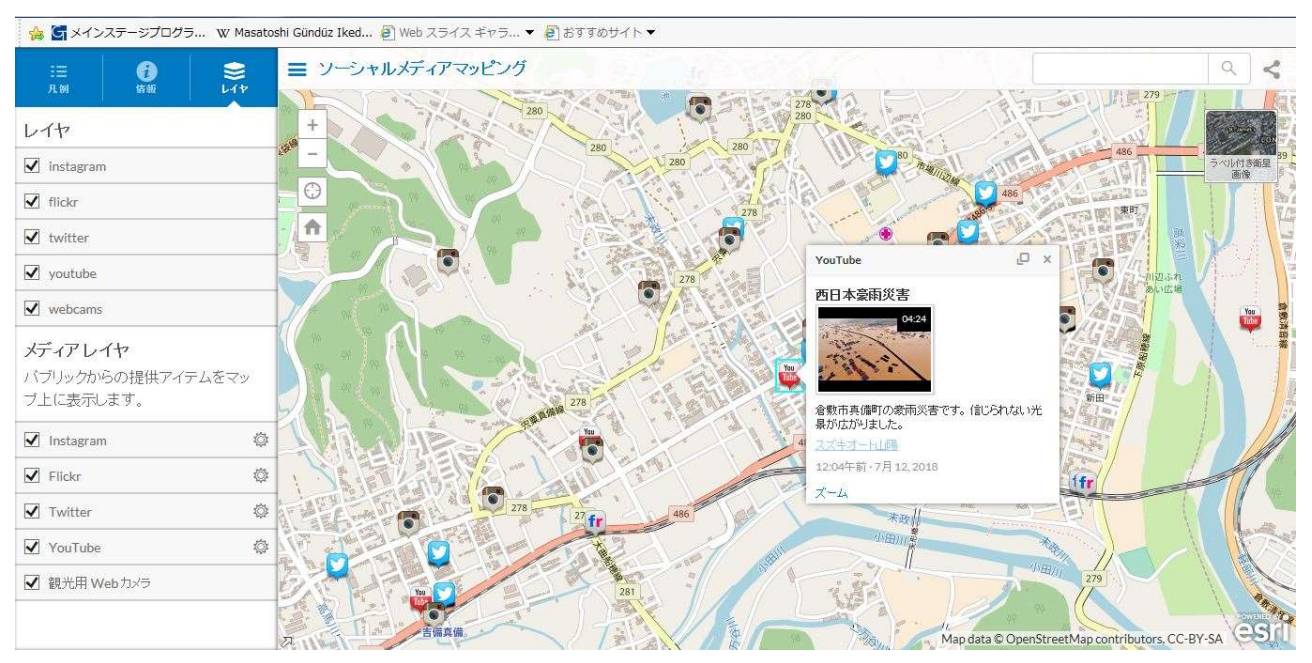

Fig. 4. Information related to the seriously damaged area in Mabi District, Kurashiki City, Okayama Prefecture using YouTube. 


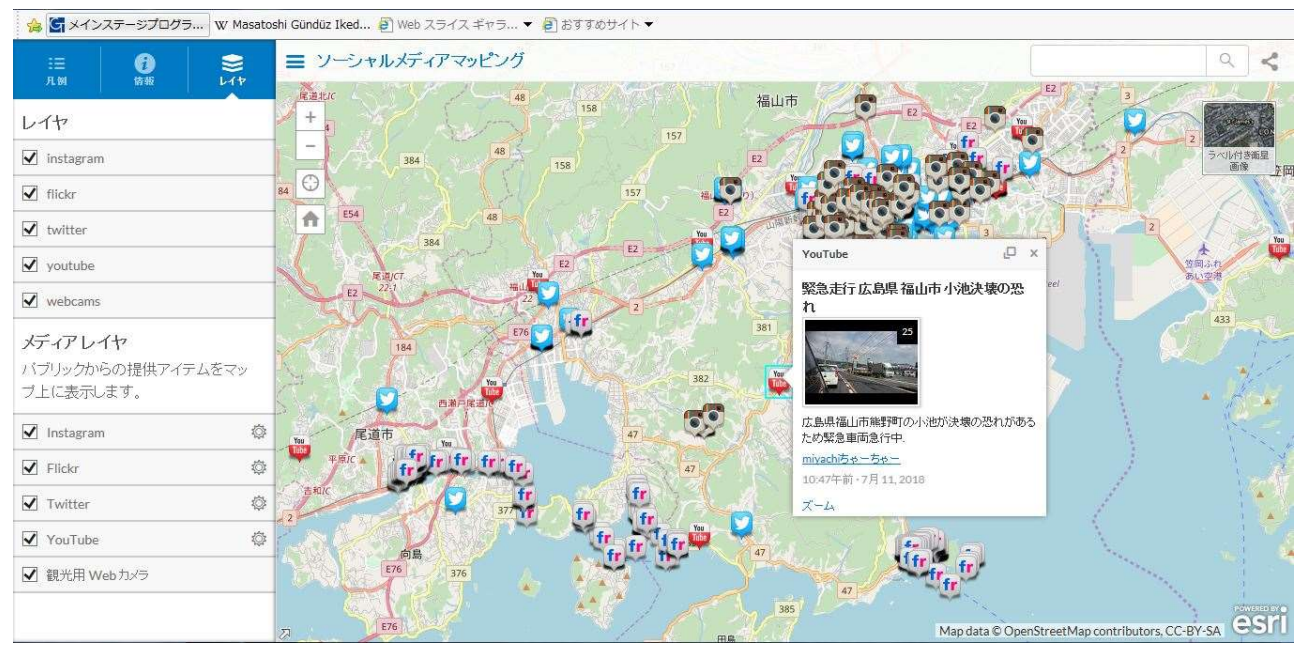

Fig. 5. Information related to the collapsed reservoir in Fukuyama City, Hiroshima Prefecture using YouTube.

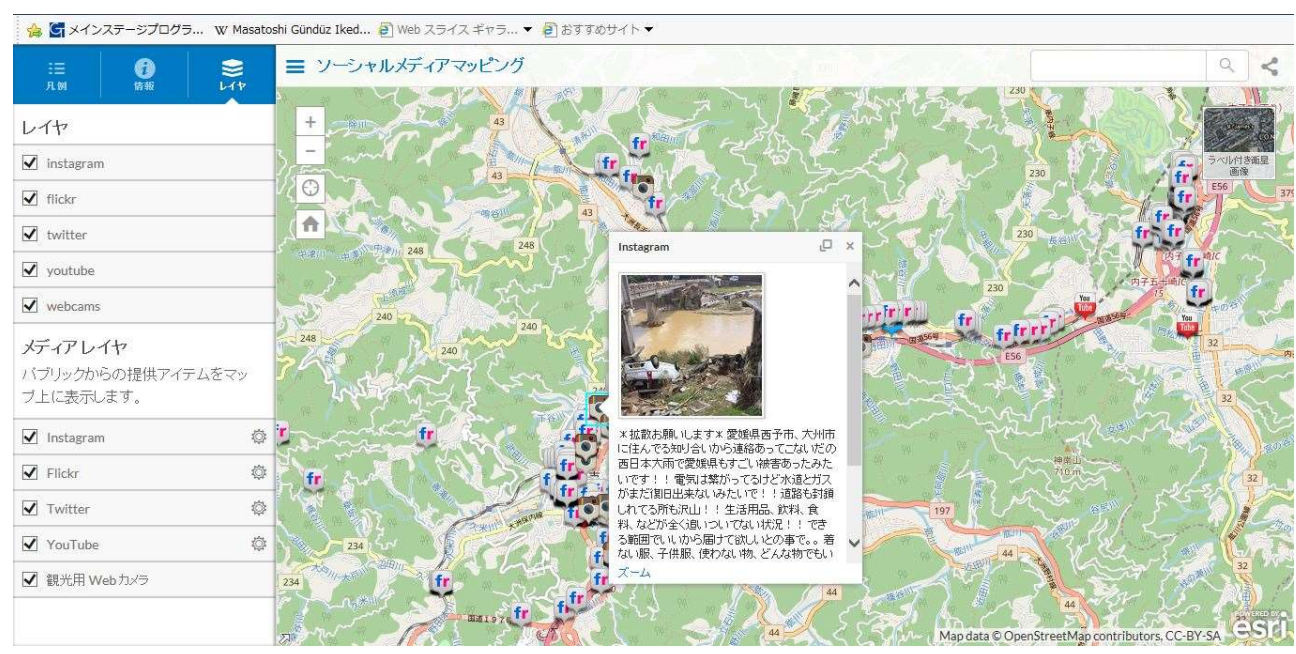

Fig. 6. Information related to the seriously damaged area in the central part of Ohzu City, Ehime Prefecture using Instagram.

For the representative examples of submitted information using social media, Fig. 4 shows the information related to the seriously damaged area in Mabi District, Kurashiki City, Okayama Prefecture, which was submitted using YouTube. Mabi District is a suburban and rural area in Kurashiki City. Fig. 5. shows the information related to the collapsed reservoir in Fukuyama City, Hiroshima Prefecture, which was submitted using YouTube. Fig. 6 shows the information related to the seriously damaged area in the central part of Ohzu City, Ehime Prefecture, which was submitted using Instagram. From these figures, it is evident that important information related to stricken areas was frequently submitted using social media in real time at the time of the Heavy Rain Disaster in Western Japan in 2018. 


\section{Characteristics of the information submitted using Twitter at the time of the Heavy Rain Disaster in Western Japan in 2018}

\subsection{Classification by the kinds of hashtags at and after the times of the heavy rain disaster}

Focusing on the information submitted using Twitter, Table. 1 shows the kinds of hashtags related the Heavy Rain Disaster in Western Japan in 2018. From Table 1, it is clear that the kinds of used hashtags are largely different at and after the times of the heavy rain disaster. Additionally, though various kinds of hashtags related to the heavy rain disaster were created, some of them meant the same phenomena and damages, and that might cause confusion among users. Most of hashtags were related to specific prefectures, cities, towns and districts in the damaged area, and it is noticeable that many hashtags include the names of Hiroshima, Okayama and Ehime Prefectures, Higashihiroshima, Kurashiki and Ohzu Cities, and Mabi District and its small-scale administrative units (Aza in Japanese). Additionally, there are the most hashtags related to Mabi District shown in Table 1.

Table 1. Kinds of hashtags related the Heavy Rain Disaster in Western Japan in 2018.

\begin{tabular}{ll}
\hline Stages & Kinds of hashtags \\
\hline $\begin{array}{l}\text { At the time of the heavy rain } \\
\text { disaster }\end{array}$ & $\begin{array}{l}\text { Situation (21), Evacuee (7), Rescue request and corporation (15), } \\
\text { Name of specific place (5), Name of specific place in Mabi District } \\
\text { (4), Information transmission (6) }\end{array}$
\end{tabular}

After the time of the heavy Name of heavy rain disaster (6), Support (20), Encouragement (4), rain disaster Donation (2), Serious damage (5), Issues (10), Pets (2)

Regarding important vital information, close relatives, friends and neighbors submitted the information in place of the persons who do not have any mobile information terminals and cannot submit information by themselves. In the case, Twitter was most frequently used, and location information can be regarded as vital information.

However, some issues related to the use of Twitter were identified. First one is that there were many tweets with a hashtag in hope of diffusion, and these were retweeted by the unspecified number of users, and those might lead to excessive information and confusion. Second one is that there were some tweets which expressed personal opinions and feelings, and vague situations. As such tweets increased, it was difficult to discover really important ones.

\subsection{Kinds of hashtags related to Mabi District, Kurashiki City, Okayama Prefecture}

Based on the results in the previous sections, it is clear that Mabi District, Kurashiki City, Okayama Prefecture was heavily damaged by the Heavy Rain Disaster in Western Japan in 2018. As the serious situations in Mabi District were frequently reported by both Mass Media (TVs, newspapers and magazines) and Social media, the district attracted the general public attention. Therefore, focusing on the information submitted using Twitter and related to Mabi District, Table 2 classifies the kinds of hashtags in detail.

The heavy rainfall flood warning was announced in the western part of Japan (Nagasaki, Fukuoka, Saga, Hiroshima, Tottori, Okayama, Hyogo and Kyoto Prefectures) on July 6th. 
Additionally, the same warning was announced in Gifu, Kochi and Ehime Prefectures on July 7th. As shown in Table 2, the numbers of tweets related to Mabi District started increasing on July 6th, and most hashtags related to situation, rescue request and corporation on July 7 th and 8th. From July 9th on, many kinds of hashtags were newly created and used. It is surprising that the hashtags related to the attention reminding against false rumours and thieves were also newly created and used. After July 15 th, the numbers of tweets related to Mabi District had been gradually decreasing. The details of others are related to personal opinions and feelings, and vague situations related to the Heavy Rain Disaster in Western Japan in 2018.

Table 2. Kinds of hashtags related Mabi District, Kurashiki City, Okayama Prefecture

(July 16, 2018).

\begin{tabular}{ll}
\hline Date & Kinds of hashtags \\
\hline July 6th (Fri) & Others (1) \\
July 7th (Sat) & $\begin{array}{l}\text { Situation (6), Rescue request and corporation (24), Support (2), } \\
\text { Encouragement (4), Others (10) }\end{array}$ \\
July 8th (Sun) & $\begin{array}{l}\text { Situation (5), Support (5), Pets (1), Others (1) } \\
\text { Situation (1), Rescue request and corporation (1), Support (4), } \\
\text { Euly 9th (Mon) }\end{array}$ \\
$\begin{array}{l}\text { Eumouragement (1), Donation (1), Attention reminding against false } \\
\text { July 10th (Tue) }\end{array}$ & $\begin{array}{l}\text { Support (1), Others (3) } \\
\text { July 11th (Wed) }\end{array}$ \\
Suly 12th (Thru) & Support (2), Donation (1), Others (2) \\
July 13th (Fri) & Situation (1), Support (2), Encouragement (1), Donation (2), Others (3) \\
July 14th (Sat) & Attention reminding against thieves (2), Others (1) \\
July 15th (Sun) & Support (1) \\
\hline
\end{tabular}

\section{Rescue request using Twitter at the time of disasters}

\subsection{Utilization of Twitter at the time of the heavy rain disaster}

At the time of the Heavy Rain Disaster in Western Japan in 2018, the Twitter Japan proposed the use of tweets for rescue request, and submitted an example tweet in easy-to-understand manner from the account of Twitter lifeline. Fig. 7 shows an example tweet of rescue request using twitter proposed by the Twitter Japan on July 10th. Fig. 7 mentions that it is necessary to clearly mention concrete situation, use of hashtag \#rescue, display of images (if possible) and address in the rescue request using Twitter. The Twitter Japan did the similar volunteer activities at the time of the Great East Japan Earthquake, and the heavy rain disasters caused by Typhoons No.10 and 19 in 2019.

Fig. 8 shows a tweet with an image related to a person who was rescued by Japanese SelfDefense Forces. Similar tweets with the one shown in Fig. 8 were frequently found after the time of the Heavy Rain Disaster in Western Japan in 2018. Just after the person related to the rescue request was safety rescued, it was necessary to immediately erase the related tweet. 
Twitterライフライン@ @TwitterLifeline·7月10日 Important points Twitterで掔急救助を求める場合には、井救助ハッシュタグとともに要請内容、写 真、住所または位置情報など、具体的かつ正確な情報をつけましょう。救助が完 了したら、報告ツイートするとともに、救助要請ツイートを削除してくださ い。

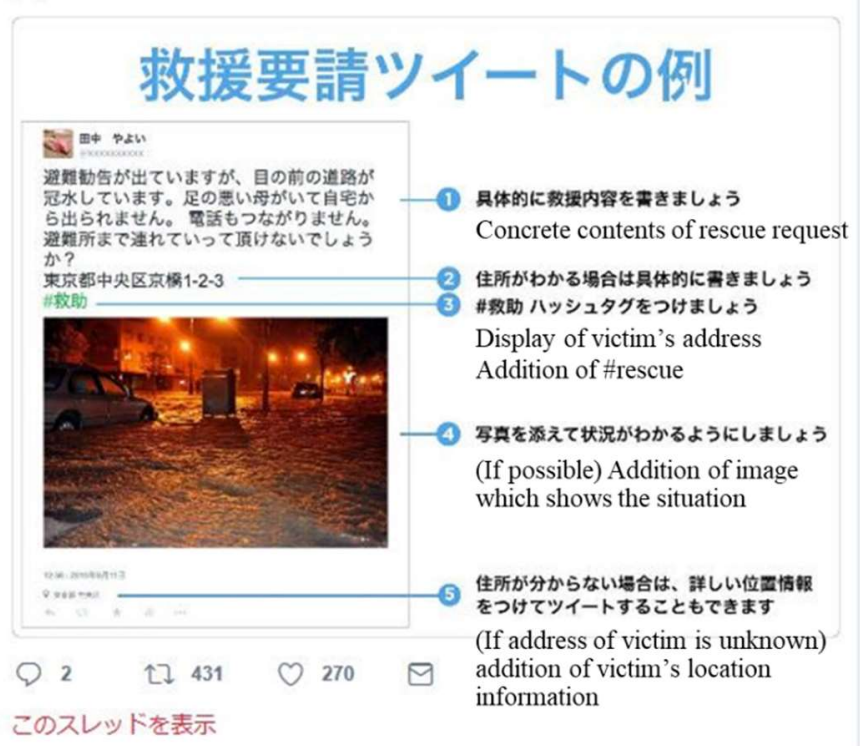

Fig. 7. Example tweet of rescue request using Twitter proposed by the Twitter Japan.

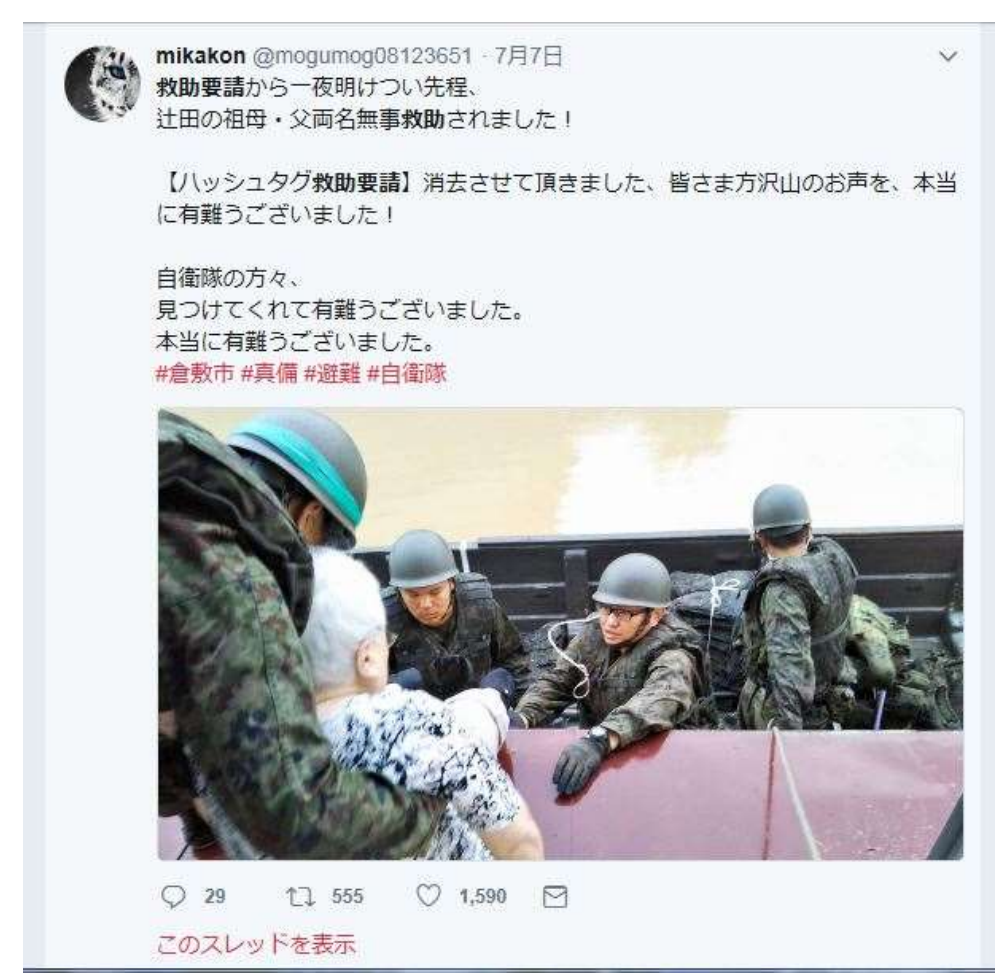

Fig. 8. Tweet with an image related to a person who was rescued by Japanese Self-Defense Forces. 


\subsection{Necessity of rules for the use of Twitter at the time of disasters}

Based on the analysis results in the previous section, and referring the utilization of social media mapping at the time of the Heavy Rain Disaster in Western Japan in 2018 in section 2 , it is essential to create the specific rules for the use of Twitter at the time of disasters which can be summarized in the following three points.

(1) Creation of the tweet formats according to the purposes of information submissions

Because it might not possible to submit appropriate information at the time of disasters, it is desirable to create the tweet formats according to the purposes of information submissions such as evacuation, rescue request and cooperation, support, donation, contribution and so on.

(2) Unification of the hashtags related to disasters

If various kinds of hashtags which mean same phenomena and damages are created by the unspecified number of users, and that might cause confusion among users. Therefore, it is necessary to prevent causing confusion among users to unify the hashtags related to disasters.

In this background, at the heavy rain disaster caused by Typhoon No.10 in October, 2019, Nagano Prefectural Government efficiently gathered the related information and rescued victims using Twitter. The department of disaster prevention and reduction used the formal Titter account to gather the information related to rescue request and corporation, and asked the victims and their close relatives, friends and neighbors to add the specific hashtag "\#Damage caused by Typhoon No.19 in Nagano Prefecture" to their tweets. As a result, it was possible for the department of disaster prevention and reduction to rescue the victims, referring approximately 50 tweets. Thus, considering the above successful example at the time of the heavy rain disaster, it is expected to create the specific rules to utilize Twitter during the normal period without any major disasters in response to regional characteristics in the unit of local government.

(3) Learning of information literacy when submitting and receiving information

At the time of disasters, various tweets are frequently submitted by the unspecified number of users, and that might lead to excessive information and confusion. Therefore, it is necessary for users to fully consider whether they ought to tweet and retweet the information related to disaster or not. Additionally, users have to immediately erase old tweets which are not suited to the present situations by themselves.

\section{Conclusion}

Considering the circumstances in Japanese advanced information society, and taking up the function of social media mapping included in the spatiotemporal information system developed by Makino et al. (2019), the present study described the issues related to the development and utilization of digital infrastructures as one of the measures for disaster prevention and reduction. Because, at the time of the Heavy Rain Disaster in Western Japan in July, 2018, it was possible to gather and accumulate a variety of disaster information using the above function of social media mapping. First of all, the present study grasped the utilization of the social media mapping at the time of the heavy rain disaster. Secondary, the present study described the characteristics of the information submitted using Twitter at the time of the heavy rain disaster. Thirdly, based on these results, the present study grasped the utilization of Twitter at the time of the heavy rain disaster, and proposed the specific rules for the use of Twitter at the time of disasters.

In the super smart society of Japan as mentioned in section 1, a great variety of information is submitted via the Internet, and such information can easily be received and shared at "anytime", "anywhere" and with "anyone" through a variety of ICT. As the virtual space is closely involved with the real space, these mutually influence. Accordingly, when a disaster 
occurs in the real space, submission and reception of the related information using a variety of means (including both mass media and social media) are started approximately at the same time in the virtual space. Due to the close relationship between the real and virtual spaces in the above super smart society of Japan, it is possible to rescue and support victims, and cause excessive information and confusion.

Additionally, it is essential to effectively utilize the information included in the virtual space at the time of disaster. Specifically, it is an important issue to make use of the information on social media for rescue in the real space. For example, it is hopeful to assign the persons in the outside of damaged areas who can appropriately choose the important information to report it to the local government in the inside of damaged area and national government. Furthermore, it is necessary to take the measures for the people vulnerable to disaster who require the disaster information most. For this, it is necessary to prepare a variety of ICT in addition to oral communication.

As future study projects, the improvement of the system based on the results in section 2.1, as well as the enhancement of the significance of using the system by gaining more data from other areas inside and outside Japan, can be raised. Based on the result, it is desirable to verify the validity of the specific rules proposed for the use of Twitter at the time of disasters in section 4.2.

\section{References}

1. Cabinet Office (2016) The 5th Science and Technology Basic Plan. 56p.

2. Cabinet Office (2013) Consumer Confidence Survey. https://www.esri.cao.go.jp/jp/stat/shouhi/shouhi.html. (accessed on 17 March 2020).

3. Ryuhei Makino and Kayoko Yamamoto (2019) Spatiotemporal Information System Using Mixed Reality for Area-Based Learning and Sightseeing. Stan Geertman, Andrew Allan, Chris Pettit, John Stillwell (eds.) Lecture Notes in Geoinformation and Cartography: Computational Urban Planning and Management for Smart Cities. Springer, pp.283-302. 